\title{
Desenvolvimento de objetos de aprendizagem para dispositivos móveis: uma nova abordagem que contribui para a educação.
}

\author{
Leandro Ramos de Oliveira ${ }^{1}$ \\ Roseclea Duarte Medina ${ }^{1}$ \\ ${ }^{1}$ Centro de Tecnologia - Universidade Federal de Santa Maria (UFSM) \\ leandroo@inf.ufsm.br, rose@inf.ufsm.br
}

\section{Resumo}

O desenvolvimento de objetos de aprendizagem, sempre foi um bom exemplo do emprego da tecnologia na educação. No entanto, com os avanços tecnológicos, novos ambientes de trabalho estão expandindo e com cada vez mais aceitação entra as pessoas. Exemplo disso são os dispositivos móveis como telefones celulares e PDAs. Percebendo esta expansão, empresas de desenvolvimento estão criando novas ferramentas que permitam a produção de materiais para tais dispositivos. Aliando todas estas áreas, chega-se a idéia de desenvolvimento de objetos de aprendizagem para dispositivos móveis, que até então não havia sido abordada.

Palavras chaves: objetos de aprendizagem, dispositivos móveis, Flash Lite.

\section{Development of learning objects for mobile devices: a new approach for spreading education}

\begin{abstract}
The development of learning objects has always been a good example for the use of technology in education. However, with technological advances, new working environments are expanding, more and more accepted by the people. An example for these are mobile devices, like cell phones and PDAs. Perceiving this expansion, development companies are creating new tools which allow the production of materials for these devices. Uniting all those areas, the idea of developing objects for learning for mobile devices emerges, which until then had not been tackled.
\end{abstract}

Keywords: learning objects, mobile devices, Flash Lite.

\section{Introdução}

Uma das formas em que a tecnologia incentiva, apóia e estimula a educação, é através de objetos de aprendizagem. Tais ferramentas auxiliam professores na 
elaboração e condução de aulas interativas e dinâmicas, onde os alunos são capazes de assimilar difíceis conceitos de uma forma simples, porém bastante eficaz.

No entanto, com o novo paradigma das tecnologias para dispositivos móveis, percebeu-se um novo ambiente/tecnologia onde os profissionais da educação poderiam se valer para divulgar o conhecimento. Uma das maneiras para isso é através do desenvolvimento de objetos de aprendizagem para serem executados em dispositivos móveis como celulares e PDAs.

Este artigo tem como objetivo apresentar um levantamento sobre os conceitos e estado atual de desenvolvimento no Brasil de objetos de aprendizagem para dispositivos móveis e uma plataforma de desenvolvimento para este novo ambiente. Além disso, é divulgada uma análise da forma em que hoje em dia os objetos educacionais presentes na Internet são visualizados em aparelhos como telefones celulares e PDAs. E ainda, uma alternativa de implementação de um objeto totalmente pensado para tais dispositivos.

\section{Objetos de aprendizagem}

Um dos maiores e mais antigos desafios enfrentados pelos professores em âmbito geral, é o de descobrir diferentes formas de transmitir um conhecimento para seus alunos, e ainda, dentre estas formas, escolher a que melhor se aplica para a apresentação de determinado conteúdo. Com a evolução tecnológica vigente, e a grande difusão da Internet que possibilitou o acesso rápido aos mais variados tipos de informações, os educadores passaram a contar com estes recursos como novas ferramentas para ajudá-los a transpor este desafio.

Por volta do ano 2000, já era possível o acesso via rede mundial de computadores a conteúdos educacionais que representavam os primórdios deste novo nicho de atuação no campo da educação. Desta forma, surgiram equipes multidisciplinares, formadas por professores, designers, programadores, dentre outros profissionais, que buscam conciliar diferentes conhecimentos em prol de uma meta comum, que é o desenvolvimento dos chamados Objetos de Aprendizagem.

Segundo o grupo Learning Objects Metadata Workgroup do Institute of Electrical and Electonics Engineers (IEEE), define-se Objetos de Aprendizagem (Learning Objects) como "qualquer entidade, digital ou não digital, que possa ser utilizada, reutilizada ou referenciada durante o aprendizado suportado por tecnologias" (IEEE, 2005). Estes objetos podem ser utilizados de uma forma individual, como ferramentas de fixação de um determinado conteúdo por um único aluno, ou de uma forma coletiva, aplicada a uma turma de alunos. Dentro desta última, ainda pode-se optar pela utilização do objeto tanto como um complemento para as atividades desenvolvidas em sala de aula, quanto para a elaboração completa de uma aula, caso tenha sido desenvolvido um guia de atividades pedagógicas que descreva a utilização do objeto durante a mesma.

No Brasil, um dos programas de desenvolvimento de objetos de aprendizagem mais conhecidos, é a Rede Interativa Virtual de Educação (RIVED), pertencente à Secretaria de Educação a Distância (SEED). O RIVED, além de produzir conteúdos pedagógicos digitais, também realiza treinamentos e capacitações em instituições de 
ensino superior e na rede pública de ensino, sobre a metodologia de produção e utilização de objetos educacionais para a educação básica (Ensino Médio).

Durante os últimos anos, foram produzidos diversos conteúdos educacionais por instituições, grupos de desenvolvimento, etc., que muitas vezes disponibilizam tais conteúdos na Internet, em sites (de modo geral), ou em repositórios de objetos como é o caso do programa RIVED, permitindo desta forma que todo este material possa ser acessado a qualquer hora e em qualquer lugar.

Recentemente um novo conceito passou a ser amplamente discutido no meio educacional, a chamada M-Learning ou Mobile Learning. Esta se refere basicamente ao fato de se utilizar tecnologias de rede sem fio para difundir o ensino e a aprendizagem, facilitando ainda mais o acesso a informações, visto que agora se trabalha sobre o conceito de mobilidade e/ou liberdade geográfica.

Com base nos ideais de m-learning, professores e equipes desenvolvedoras de objetos educacionais deparam-se agora com uma nova plataforma de desenvolvimento que está em plena expansão e é objeto de estudos e pesquisas incluindo os fabricantes de dispositivos móveis.

A seguir, é feita uma explanação sobre este novo meio de desenvolvimento, que são os dispositivos móveis. Exaltando suas vantagens, desvantagens e contribuições para o desenvolvimento de objetos de aprendizagem.

\section{Dispositivos móveis}

Durante as últimas décadas, pôde-se perceber um aumento significativo na utilização de dispositivos móveis para diversas finalidades. Dispositivos tais como PDAs (Personal Digital Assistants) e celulares são cada vez mais comuns nas mãos das pessoas. A principal questão é que cada um dos dispositivos pertencentes à vanguarda destes, era fabricado com uma finalidade específica, que inclusive já vinha programada em seu hardware (sistemas baseados em hardware), o que restringia bastante sua utilização. Exemplos disto são os primeiros MP3s, que apenas reproduziam os arquivos de áudio, e os primeiros celulares que não permitiam nada além da realização de chamadas. Porém, com o aumento do poder computacional, tornou-se possível o surgimento de novos ambientes de programação focados neste tipo de equipamento, onde é possível desenvolver aplicações quase que totalmente independentes de dispositivo e fabricante. Esta "generalização" referente ao desenvolvimento para dispositivos móveis permitiu que surgissem aplicações que eram conhecidas em ambiente desktops, também estivessem disponíveis neste novo tipo de plataforma. Além de aplicações tornou-se possível também o pleno acesso a Internet, facilitando ainda mais o alcance aos mais variados tipos de informações. Dentre estas tantas informações disponíveis na internet, sentiu-se a necessidade de visualizar e executar os objetos de aprendizagem também em dispositivos móveis.

A possibilidade de utilização de tecnologias móveis no processo de ensino e aprendizagem permite o acesso a conteúdos educacionais em qualquer lugar e a qualquer hora, aproveitando assim horários livres tais como de espera ou de locomoção. Além disso, cada variante dos dispositivos móveis traz vantagens diferentes. Os telefones celulares, por exemplo, por serem aparelhos já bastante difundidos no mercado e com preços relativamente acessíveis, permitem que diferentes pessoas, tanto 
de faixas etárias distintas quanto de classes sociais diversas, tenham acesso fácil aos conteúdos educacionais. Já equipamentos como PDAs, por possuírem poder computacional e de armazenamento superiores que os telefones celulares, permitem a execução de objetos educacionais mais elaborados e até o armazenamento de conteúdos afins.

Em contrapartida as várias vantagens que a mobilidade nos apresenta, é necessário ressaltarmos as limitações de tais dispositivos, tanto em relação aos recursos de hardware quanto aos de software e interatividade. Abaixo serão destacadas algumas destas limitações em termos gerais.

\subsection{Limitações de processamento}

Os telefones celulares mais atuais são equipados com processadores que atingem uma velocidade de cerca de $300 \mathrm{MHz}$ e a expectativa é que em breve superem os $500 \mathrm{MHz}$. Já os PDAs disponibilizam velocidades superiores que esta, porém para ambos os casos, tais velocidades são visivelmente menores que as atingidas por computadores desktop. Isto impede o desenvolvimento de aplicações que exijam um processamento rápido e de uma grande quantidade de dados.

\subsection{Limitações de memória}

Uma grande quantidade de memória exige ainda um grande tamanho físico. Este fator é agravado quando tratamos de memórias para dispositivos móveis, pelo fato de estes serem equipamentos pequenos.

\subsection{Limitações de tela}

Uma importante limitação tanto em telefones celulares como PDAs é o tamanho da tela. Devido à pequena área de trabalho, as aplicações desenvolvidas para estes dispositivos não podem ultrapassar determinados limites tanto na horizontal, quanto na vertical, que variam conforme o aparelho. Ignorar tais limites acarretará no surgimento de barras de rolagem que tornam a interação com o usuário nada ergonômica.

\subsection{Limitações de software}

Em relação aos recursos de software, estes são restritos aos limites funcionais do sistema operacional existente em cada dispositivo móvel. Estes sistemas são os responsáveis por prover recursos multimídia, gráficos, serviços relacionados à manipulação de dados, dentre outras funcionalidades.

\subsection{Expectativa de usuário}


Devido ao fato de que todo recurso presente em dispositivos móveis estar sempre disponível, ou seja, sem a necessidade de um tempo de espera de inicialização como ocorrem em sistemas desktop, os usuários de tais dispositivos são pouco tolerantes a grandes tempos de resposta. Isto acaba por influenciar consideravelmente o projeto uma aplicação para este tipo de arquitetura, que deve buscar atingir uma boa expectativa do usuário.

\subsection{Análise geral}

Como o observado nesta seção, durante o desenvolvimento de aplicações para dispositivos móveis, deve-se explorar ao máximo o fator da mobilidade dentro de limites que implicam na utilização equilibrada dos recursos disponíveis, sempre ciente das expectativas a serem atingidas para plena satisfação dos usuários finais. Porém, para que se obtenha êxito nestas circunstâncias, a escolha de uma boa plataforma de desenvolvimento é imprescindível. Na próxima seção, é apresentada a plataforma Flash Lite, que foi a escolhida para o desenvolvimento das atividades deste trabalho. Será apresentada uma visão geral sobre a mesma, e o motivo da sua escolha para o desenvolvimento de objetos de aprendizagem para dispositivos móveis.

\section{Plataforma Flash Lite}

A antiga Macromedia Flash, atual Adobe Flash, é uma plataforma pertencente à empresa Adobe Systems Incorporated, onde designers e programadores são capazes de desenvolver desde simples apresentações até complexas aplicações. É uma boa alternativa para produção de recursos a serem executados na Internet, isto pelo fato dos arquivos gerados serem bastante pequenos.

Pioneiro no desenvolvimento de aplicações web com características de aplicações desktop, as chamadas RIAs (Rich Internet Applications), o Flash inovou com o lançamento de aplicações que rodam direto nos navegadores de Internet, sem a necessidade de instalação de programas adicionais. Acrescenta-se ainda o grande poder de desenvolvimento fornecido pela linguagem Actionscript, utilizada em produções Flash.

Dentre os inúmeros recursos que foram surgindo e sendo agregados a esta plataforma, podemos destacar a fração do Flash dedicada ao desenvolvimento para dispositivos móveis, que é um dos escopos deste artigo, o Flash Lite.

Flash Lite (Adobe Systems Incorporated, 2006b) é uma tecnologia toda projetada para dispositivos móveis, onde busca aliar uma boa performance de processamento com os poucos recursos apresentados por tais dispositivos. Atualmente está disponível em duas versões: Flash Lite 1.0 e Flash Lite 1.1 baseados no Flash Player 4, e Flash Lite 2 baseado no Flash Player 7.

Segundo documento divulgado pela Adobe, dentre os vários recursos disponibilizados no Flash Lite 2 podemos destacar o suporte a conexões via sockets, manipulação de arquivos XML, suporte a Actionscript 2.0, formatação de texto 
melhorada e suporte a Unicode. Além disso, possui recursos de multimídia (imagem, áudio e vídeo) e armazenamento de dados para reuso (Adobe Systems Incorporated, 2007).

Ainda, o Flash Lite facilita bastante o trabalho de profissionais que já desenvolviam conteúdos em Flash para ambientes desktop. Isto porque, tais profissionais, podem se valer do conhecimento adquirido relativo ao desenvolvimento na plataforma Flash para realizarem trabalhos para dispositivos móveis.

Porém, como qualquer plataforma emergente, o Flash Lite, segundo Ricardo Menezes em artigo publicado no site MobileZone, ainda apresenta alguns pontos negativos a serem considerados. Pontos tais como: indisponibilidade, que se refere ao fato de poucos celulares apresentarem suporte a conteúdos Flash Lite, principalmente no Brasil; inconsistência de versões: dependendo do aparelho, marca e sistema operacional, o Flash Lite não poderá ser visualizado plenamente em todos seus modos; política de distribuição: o fato de usuários que compram aparelhos que saem de fábrica sem suporte ao Flash Lite terem de pagar dez dólares para obtê-lo, dificulta a aceitação da tecnologia; e limitações do plug-in: o Actionscript presente no Flash Lite oferece uma gama menor de recursos comparado a sua versão desktop (Menezes, 2006).

Mesmo assim, o Flash Lite permite a criação de interfaces ricas e muito bem elaboradas em poucos minutos, além de não exigir um grande conhecimento de programação para tal finalidade. Devido principalmente a esta característica, é que o Flash Lite é melhor escolha de plataforma para se desenvolver objetos de aprendizagem para dispositivos móveis.

\section{Atividades desenvolvidas}

Com base neste cenário, a seguir será realizada a descrição do trabalho de desenvolvimento de objetos para dispositivos móveis. É necessário destacar que o presente trabalho se encontra na etapa inicial de desenvolvimento.

Também será apresentado como atualmente é visualizado em dispositivos móveis um objeto de aprendizagem disponível na Internet que não foi projetado para aquele tipo de ambiente seguido de uma alternativa de implementação de um objeto que possa ser plenamente visualizado em dispositivos móveis.

\subsection{Dados gerais}

Para que se possa ter uma idéia de como são apresentados os objetos disponíveis na Internet, sem ter de acessá-los diretamente de algum dispositivo móvel, tem-se a alternativa de uso de tradutores de conteúdo. Estes realizam a tarefa de adaptar um determinado conteúdo web para ser visualizado em telas menores tais como de celulares e PDAs.

Para este trabalho, foram utilizados os seguintes tradutores on-line. Ready.mobi, que utiliza testes padrões de visualização em telefones celulares definidos pelo World Wide Web Consortium (W3C), em parceria com empresas de mobilidade. E o browser Opera, que disponibiliza um recurso de tradução de páginas web para telas de PDAs. 
O objeto escolhido para esta análise foi o intitulado "No tempo certo!" (um dos disponíveis na página do Programa RIVED). Este objeto aborda conceitos de química, utiliza recursos de HTML e Flash e tem como público-alvo alunos da segunda série do Ensino Médio.

\subsection{Usando tradutores}

Como o próprio nome diz, aplicações tradutoras dedicam-se em apresentar um mesmo conteúdo de uma forma diferente, porém, é claro, mantendo suas principais características. No entanto, nem sempre tais características podem ser mantidas, ainda mais quando nos referimos à tradução de páginas web.

Na Figura 1, podemos visualizar como é apresentada a página que contém o objeto referenciado anteriormente, no browser Opera, no que podemos chamar de modo desktop, com uma resolução de 1152 por 864.

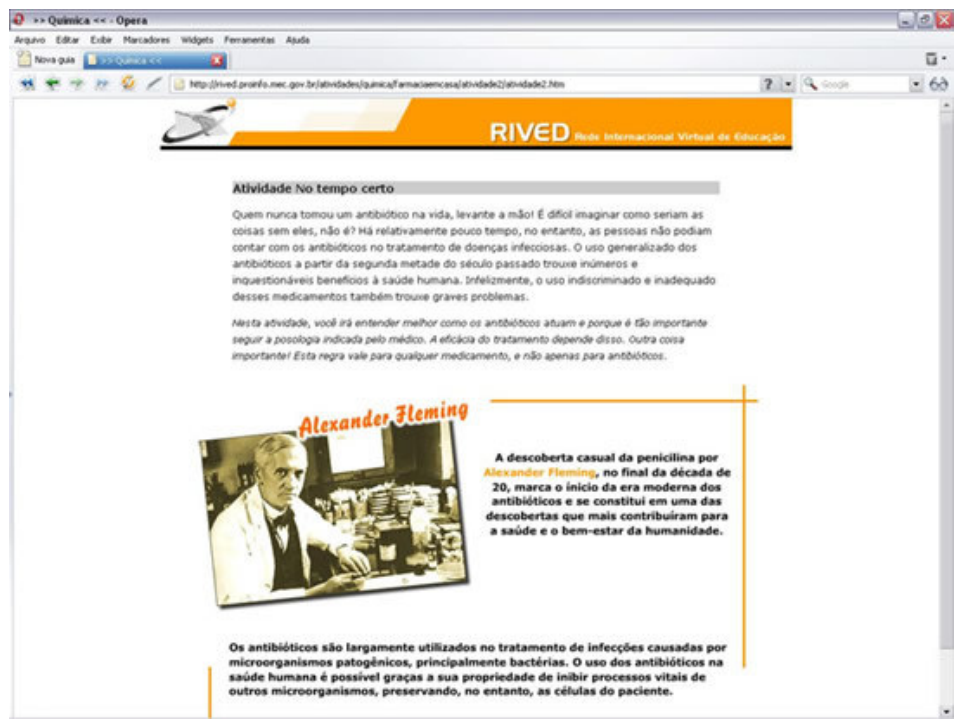

Figura 1 - Visualização de objeto em ambiente desktop.

Como o objeto foi projetado e desenvolvido para ser visualizado nesta plataforma, pode-se perceber que apresenta boas características de visualização, o que permite uma boa interação com o usuário. Agora, observemos como seria visualizado este mesmo objeto em uma tela de PDA. Isto é possível, alterando-se no browser Opera o modo de visualização. Veja a Figura 2 abaixo. 


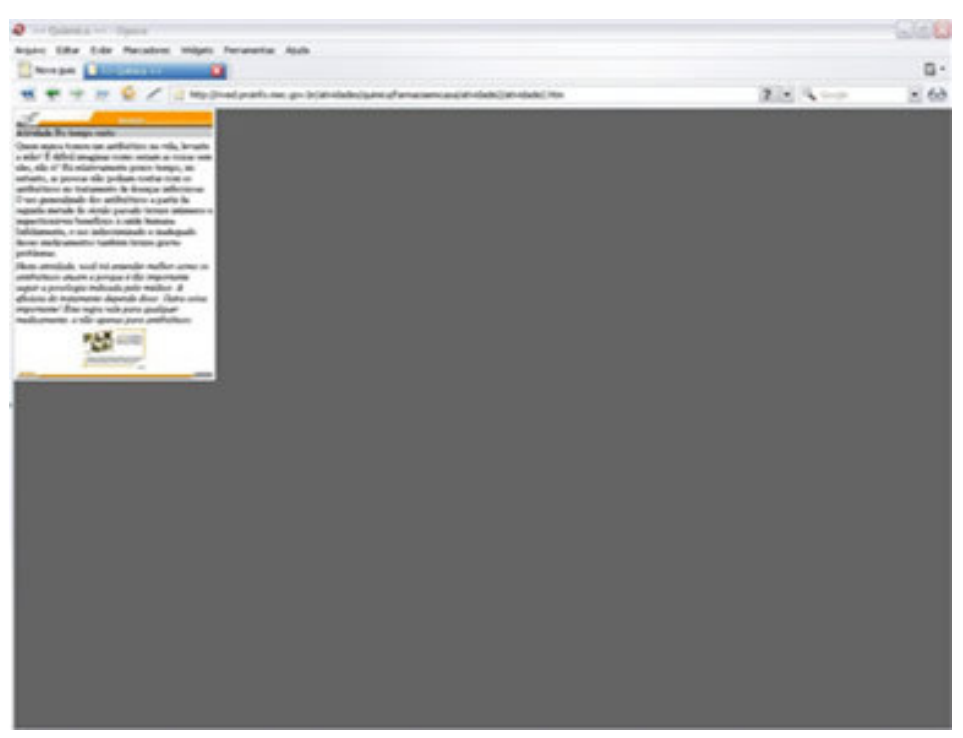

Figura 2 - Visualização de objeto em tela de PDA.

A principal característica a se observar na figura acima é a grande diferença no tamanho da área de trabalho disponível para cada plataforma. Toda a área em cinza é um espaço que não está presente, no caso, em um PDA, o que acaba por reduzir drasticamente as possibilidades de distribuição de conteúdo. Percebe-se ainda alterações consideráveis na forma de apresentação do conteúdo original. Este como um todo sofre modificações pelo fato de estar contido em um espaço menor. Além disso, os diferentes recursos utilizados são representados também de formas diferentes. Também se percebe que o conteúdo implementado em HTML sofreu poucas perdas, sendo possível de ser visualizado. Já o conteúdo feito em Flash, plataforma escolhida no desenvolvimento da maioria dos objetos de aprendizagem, perde totalmente sua qualidade e usabilidade, resultado de ter seu tamanho extremamente minimizado.

Pode-se ainda analisar a representação deste objeto em telas de dois modelos de telefones celulares como o Sony Ericsson k750 e Nokia N70. Esta visualização é obtida através do tradutor Ready.mobi, apresentada na Figura 3 abaixo.
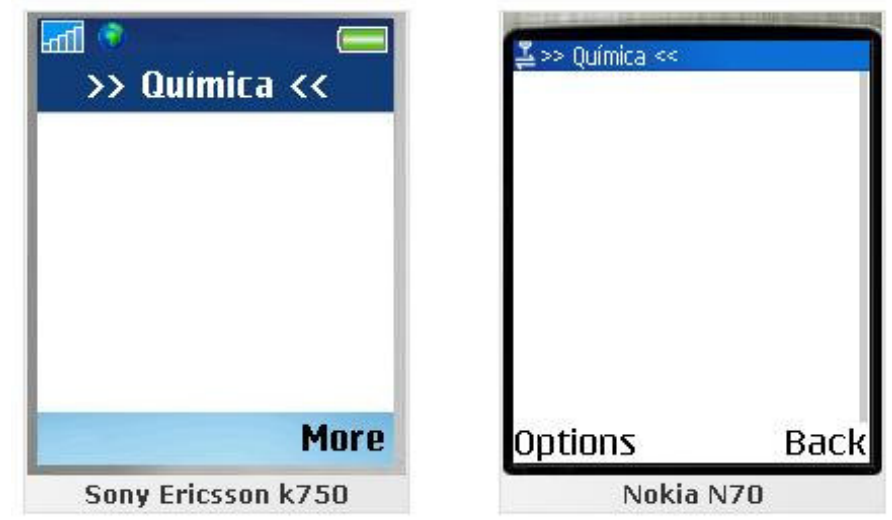

Figura 3 - Visualização de objeto em tela de celular (Sony Ericsson e Nokia). 
No caso destes dispositivos, o resultado é ainda mais preocupante. O único conteúdo visualizável é o título da página. Todo o resto do conteúdo do objeto não é disponibilizado tornando-se totalmente inútil.

\subsection{Alternativa em Flash Lite}

Em contrapartida ao péssimo modo de visualização de objetos de aprendizagem em dispositivos móveis, é apresentado uma alternativa de implementação de um provável objeto já pensado para tal ambiente.

Foi desenvolvido um esboço de um objeto de aprendizagem em Flash Lite, e testado no próprio simulador de telefones celulares presente no Flash Professional 8, apresentado Figura 4 abaixo:

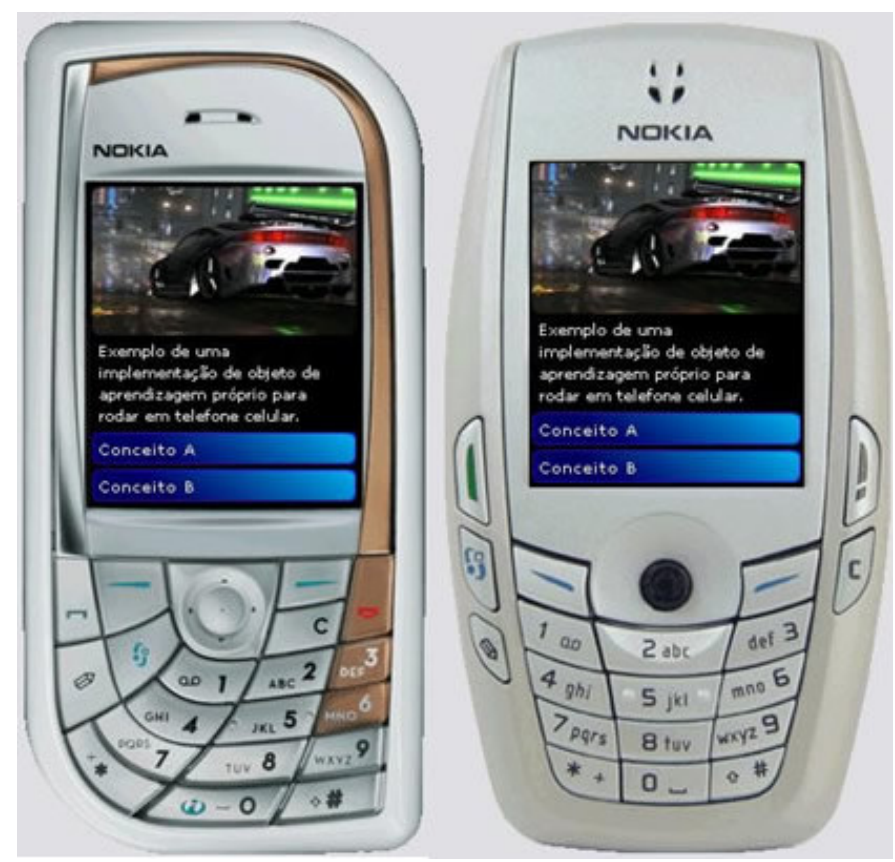

Figura 4 - Visualização de objeto próprio para celular (modelos Nokia).

Neste caso, foram escolhidos dois modelos do fabricante Nokia suportados pelo simulador presente no Flash, que são o Nokia 7610 (à esquerda) e o Nokia 6620 (à direita). O que foi desenvolvido é um protótipo de um objeto e não um objeto completo. Possui uma tela inicial com uma imagem relativa ao assunto do objeto, um texto explicativo e um menu, no caso de duas opções. O texto apresentado no objeto é meramente ilustrativo, referenciando o que realmente poderia vir escrito em cada local. Neste caso foi ativada via código a opção do objeto ser apresentado em tela cheia.

Analisando o resultado obtido, logo se percebe a grande vantagem de se utilizar o Flash Lite. O conteúdo do objeto em questão, apesar de não possuir uma grande área de trabalho, se acomoda de forma harmônica na pequena tela, e possibilita uma plena interação com o usuário. Nota-se ainda que mesmo em dispositivos diferentes, a 
visualização do conteúdo é a mesma, apesar de estarmos trabalhando com dispositivos de uma mesma empresa. Outro ponto a destacar é o alto grau de definição de imagens, design atraente e diferenciado que se pode atingir com a utilização do Flash Lite. Esta característica é imprescindível para a elaboração de bons objetos de aprendizagem, visto que estes dependem também do grau de satisfação de uso atingido pelo usuário, para que permaneça utilizando o objeto.

As atividades até aqui realizadas são apenas uma amostra inicial de tudo o que se pode desenvolver nesta área.

\section{Considerações finais}

Com base em todos os conceitos abordados neste artigo e resultados obtidos nas atividades, pode-se ter uma boa visão do amplo caminho que o desenvolvimento de objetos de aprendizagem para dispositivos móveis tem pela frente. Ao mesmo tempo em que esta forma de apresentação de objetos é algo inovador e com grandes expectativas de futuro, ela nos defronta com inúmeros obstáculos a serem vencidos neste ambiente de desenvolvimento, ainda tão pouco explorado no Brasil e de certa forma no exterior também. Pelo fato de ainda não termos referências suficientemente consistentes em relação a implementações de objetos para dispositivos móveis, bem como documentações relativas a percalços que possam surgir no momento em que deixamos de lado simuladores e passamos a usar dispositivos reais, é que se percebe a grande necessidade da realização de testes destes novos objetos direto em aparelhos celulares e PDAs.

$\mathrm{Na}$ fase final do trabalho em andamento, será realizado o desenvolvimento de objetos de aprendizagem completos através da plataforma de desenvolvimento Flash Lite. Além de visualizar estes em simuladores, pretende-se implementá-los em dispositivos equipados com o Flash Player para que se perceba a forma real de visualização que é permitida atingir. Além disso, é possível através destes testes em ambientes reais a geração de uma documentação detalhada e com um bom embasamento sobre o assunto, permitindo assim alavancar novos trabalhos na área.

\section{Referências bibliográficas}

Legget, R.; Boer, D., W.; Janousek, S. Foundation Flash Applications for Mobile Devices. New York: 2006.

Mikkonen, T. Programming Mobile Devices An Introduction For Practitioners. Chichester: 2007.

Bevilacqua, F. Jogo de Estratégia Multi-jogador para Telefones Celulares, no Estado do Rio Grande do Sul. Santa Maria: UFSM, 2007. 57p. Trabalho de Graduação.

Labigalini, M., R. O que é WIRELESS e WAP? Campinas: 2002. Disponível em: $<$ http://www.unicamp.br/cemeq/engenharia/treinamentos/wap.html $>$. Acesso em: 20 jun. 2007. 
Pelissoli, L.; Loyolla W. Aprendizado Móvel (M-learning): Dispositívos e Cenários. São Paulo: 2004. Disponível em: <http://www.abed.org.br/congresso2004/por/htm/074TC-C2.htm>. Acesso em: 21 jun. 2007.

Menezes, R. Flash Lite - Uma nova revolução à vista? 2006. Disponível em: $<\underline{\mathrm{http}}$ ://infomediatv.terra.com.br/infomediatv/?section=11\&article=6 $>$. Acesso em: 20 jun. 2007.

IEEE. Institute of Electrical and Electonics Engineers. Apresenta textos sobre objetos de aprendizagem. Disponível em: <http://ltsc.iee.org/wg12/index.html>. Acesso em: 18 jun. 2007.

RIVED. Rede Interativa Virtual de Educação. Apresenta textos sobre objetos de aprendizagem. Disponível em: <http://rived.proinfo.mec.gov.br/>. Acesso em: 19 jun. 2007.

RIVED. Rede Interativa Virtual de Educação. Objeto de aprendizagem "No tempo certo!". Disponível em: $<$ http://rived.proinfo.mec.gov.br/atividades/quimica/farmaciaemcasa/atividade2/ativida de2.htm>. Acesso em: 19 jun. 2007.

WIKIPEDIA. A Enciclopédia Livre. Apresenta textos sobre objetos de aprendizagem. Disponível em: <http://pt.wikipedia.org/wiki/Objeto_de_aprendizagem>. Acesso em: 19 jun. 2007.

WIKIPEDIA. A Enciclopédia Livre. Apresenta textos sobre a plataforma Flash. Disponível em: <http://pt.wikipedia.org/wiki/Adobe_Flash>. Acesso em: 19 jun. 2007.

ADOBE SYSTEMS INCORPORATED. Adobe Flash Lite. Disponível em: $<$ http://www.adobe.com/products/flashlite/>. Acesso em: 20 jun. 2007.

ADOBE SYSTEMS INCORPORATED. Adobe Flash Lite 2.1 Datasheet. Disponível em: $\quad<$ http://www.adobe.com/products/flashlite/productinfo/overview/datasheet.pdf $>$. Acesso em: 20 jun. 2007.

READY MOBILE. Simulador de de telefone celular. Disponível em: $<$ http://ready.mobi/launch.jsp?locale=en EN>. Acesso em: 19 jun. 2007.

OPERA SOFTWARE. Navegador Opera. Disponível em: <http://www.opera.com/company/>. Acesso em: 19 jun. 2007. 